\title{
Erratum to: Palatable food consumption in children: interplay between (food) reward motivation and the home food environment
}

\author{
Annelies De Decker ${ }^{1}$ - Sandra Verbeken ${ }^{2}$ Isabelle Sioen ${ }^{1,3}$ - Wendy Van Lippevelde ${ }^{1}$. \\ Caroline Braet ${ }^{2} \cdot$ Gabriele Eiben $^{4}$ - Valeria Pala ${ }^{5}$. Lucia A. Reisch ${ }^{6}$. \\ Stefaan De Henauw ${ }^{1,7}$ • on behalf of the I. Family Consortium
}

Published online: 11 April 2017

(C) Springer-Verlag Berlin Heidelberg 2017

\section{Erratum to: Eur J Pediatr}

DOI 10.1007/s00431-017-2857-4

The original version of this article unfortunately was published with errors in the author name section. The names Gabrielle Eiben and Lucia A. Reish should be Gabriele Eiben and Lucia A. Reisch, respectively. The correct author names are now presented in this erratum.

The online version of the original article can be found at $\mathrm{http}: / \mathrm{dx} / \mathrm{doi}$. org/ 10.1007/s00431-017-2857-4.

Annelies De Decker

Annelies.DeDecker@UGent.Be

Sandra Verbeken

Sandra.Verbeken@UGent.Be

Isabelle Sioen

Isabelle.Sioen@UGent.Be

Wendy Van Lippevelde

Wendy.VanLippevelde@UGent.Be

Caroline Braet

Caroline.Braet@UGent.Be

Gabriele Eiben

Gabriele.Eiben@medfak.gu.se

Valeria Pala

Valeria.Pala@ istitutotumori.mi.it

Lucia A. Reisch

lr.ikl@cbs.dk

Stefaan De Henauw

Stefaan.DeHenauw@UGent.Be
1 Faculty of Medicine and Health Sciences, Department of Public Health, Ghent University, De Pintelaan 185 UZ 4 K3, 9000 Ghent, Belgium

2 Faculty of Psychology and Educational Sciences, Department of Developmental, Personality and Social Psychology, Ghent University, Henri Dunantlaan 2, 9000 Ghent, Belgium

3 Faculty of Bioscience Engineering, Department of Food Safety and Food Quality, Ghent University, Coupure links 653, 9000 Ghent, Belgium

4 Department of Public Health and Community Medicine, University of Gothenburg, Box 453, 40530 Gothenburg, Sweden

5 Department of Preventive and Predictive Medicine, Fondazione IRCSS Istituto Nazionale dei Tumori, Via Venezian 1, 20133 Milan, Italy

6 Department of Intercultural Communication and Management, Copenhagen Business School, Porcelaenshaven 18a, 2000 Frederiksberg, Denmark

7 Department of Health Sciences, Vesalius, University College Ghent, Keramiekstraat 80, 9000 Ghent, Belgium 